\title{
DNA Polymerases as Engines for Biotechnology
}

BioTechniques 31:370-383 (August 2001)

\section{Scott C. Hamilton, Joseph W. Farchaus, and Maria C. Davis Amersham Pharmacia Biotech, Piscataway, NJ, USA}

\section{INTRODUCTION}

Advances in biotechnology have enabled the research community to uncover and accumulate vast amounts of data at an ever-increasing pace. Obtaining the sequence of the human genome was once a "Holy Grail" project. Now that the draft sequence is available well ahead of schedule, it is evident that the work has only just begun-the greater the continent of knowledge, the greater is the shore of the unknown. Having the sequence of a representative human genome fuels the search for the differences between individuals; it is the hope of pharmacogenomics that these differences between individuals can be harnessed for prognostic and therapeutic purposes. Sequence comparisons of model organisms in which genetic manipulations can be done with ease, such as the mouse, the worm, and the fruit fly, will accelerate attempts at discovering gene function. Obtaining the sequences of microbes will display the diversity of life and perhaps uncover clues to its origin.

This review will examine the class of enzymes that has been an essential tool for molecular biology research, the DNA polymerases. A brief examination of the flow of a genome project will reveal the need for polymerases at every step. To prepare templates for sequencing, amplification is frequently used, and sequencing itself is an adaptation of the replication function of polymerase. To accelerate the process of gene discovery, the reverse transcriptase activity of DNA polymerases has been exploited to look at transcription by making cDNA. Shortcuts to cloning can be made with PCR even if a limited amount of sequence information is available. Mutagenesis is a powerful technique to understand gene function, and polymerases play a key role in constructing gene variations in vitro, by site directed and random mutagenesis.

Advances in genetic engineering of DNA polymerases will be explored, which have led to the acceleration of the pace of genome projects. These include improved polymerases for DNA sequencing, for amplification, and for reverse transcription. These applications have increasingly specialized demands for polymerases. Characteristics such as nuclease activity, thermostability, processivity, strand displacement activity, and fidelity are important in some roles but unneeded or undesired in others. Polymerases can be tailored to incorporate modified nucleotides as well. The biotech industry strives to fill these niches by engineering changes in the current repertoire of polymerases and by prospecting a diverse microbial world for new and promising enzymes. Before looking at improvements related to specific applications, a background will be given on the multiple families of DNA polymerases and their com mon structural elements and activities.

\section{BACKGROUND}

Braithwaite and Ito (16) have segregated DNA polymerases into four families: A, B, C, and X. Families A, B, and 
$\mathrm{C}$ are arranged based on their amino acid sequence homologies to $E$. coli polymerases I, II, and III, respectively. Family $\mathrm{X}$ has no homologous E. coli polymerase.

Family A includes E. coli pol I, which has roles in recombination, repair, and replication; phage polymerases such as T5 and T7; and mitochondrial DNA polymerase pol gamma. These polymerases have simple subunit structures, usually a single subunit.

Family B includes E. coli pol II; Archaeal polymerases such as Pyrococcus furiosus ; $\phi 29$ and T4 phage polymerases; eukaryotic polymerases, $\alpha, \Delta$, $\varepsilon$, and many viral polymerases. Pol IIs have DNA repair roles and are usually single-subunit enzymes. Exceptions are the eukaryotic pol $\alpha, \Delta, \varepsilon$, which are all multiple-subunit enzymes and have roles in DNA replication.

Family $\mathrm{C}$ includes polymerases that are homologous to either $\alpha$ or $\varepsilon$ subunits of the E. coli pol III. Together with the smaller subunit $\theta$, these three subunits make up the pol III core. Pol III has at least seven accessory proteins and is the main replicative polymerase of $E$. coli (55). This family can be subdivided into three classes (43): Class 1, in which $\alpha$ and $\varepsilon$ are separate subunits; Class 2, in which they are combined into one unit; and Class 3, in which they are expressed as separate proteins and joined by intein splicing (106). The placement of each functional domain within the primary sequence varies from class to class.

Family X was established to contain pol $\beta$, a eukaryotic repair enzyme that has no corresponding $E$. coli DNA polymerase (16). While its primary amino acid sequence places it in a unique family, pol $\beta$ can carry out some pol I-type functions. When the gene encoding pol $\beta$ is included in a plasmid containing an $E$. coli origin of replication, expression of the polymerase can confer plasmid maintenance in the absence of functional pol I (87). In addition, pol $\beta$ is capable of gap filling between Okazaki fragments, as well as excision repair $(85,86)$.

New polymerases continue to be discovered. Occasionally, their sequence-based placement into one of the above families proves difficult. Eukaryotic pols $\eta$ and $\tau$ do not fit well into the first four categories; however, they are homologous to two newly discovered E. coli polymerases that are designated pol IV and V $(44,94,101)$. E. coli DNA polymerases IV and V, the yeast proteins Rev1 and Rad30, and eukaryotic polymerases $\xi, \eta, \theta$, and $\tau$ form a group of loosely homologous enzymes involved in damage bypass replication $(37,44)$. These enzymes have specialized activities such as the replication of abasic or thymine dimer sites. In 1997, Uemori and colleagues (99) discovered a novel DNA polymerase with two subunits in Pyrococcus furiosus. This enzyme was discovered by polymerase activity and not by sequence identity with previously known polymerases.

Table 1 describes the classification and characteristics of widely used DNA polymerases. The polymerases from families $\mathrm{A}$ and $\mathrm{B}$ have seen the most utility in the biotech industry, particularly those with a single subunit. There are several advantages to working with the single subunit polymerases from these groups. Cloning these proteins from new species is simplified, as are construction of expression vectors and protein purification. There are regions in the pol I sequence that are sufficiently conserved to allow amplification from a variety of bacterial genera (98).

A survey of the tertiary structures of DNA polymerases suggests a more ordered picture than does a comparison of their primary sequences. While primary sequences and function have diverged, the structural similarities remain. In fact, family $X$ may have developed a structure similar to the other families through convergent evolution (47). The collection of higher-resolution structural data continues to expand, and researchers have been able to co-crystallize polymerases with their duplex DNA substrates $(27,50)$. In one case, the crystals were shown to be biologically active and capable of nucleotide incorporation and translocation (50). Co-crystallization of $\mathrm{T} 7$ DNA polymerase with template and ddNTP gives structural insights as to how it can incorporate the chain-terminating nucleotide with an activity that is thousands-fold higher than many other family A polymerases (27). Recently, Kornberg and colleagues (22) have succeeded in obtaining a structure for the first multiple-subunit polymerase, a 10-subunit RNA polymerase from Saccharomyces cerevisiae.

It is the monomeric DNA polymerases from families $\mathrm{A}$ and $\mathrm{B}$ that have been the most useful engines for biotechnology. Polymerase function can be considered to be modular. Activities such as the $5^{\prime} \rightarrow 3^{\prime}$ exonuclease activity of pol I or the RNase $\mathrm{H}$ activity of reverse transcriptases are found either in separate domains or separate subunits and are not part of the structure of the polymerase domain. A mini-review by Joyce and Steitz (47) elaborates on the common structures of polymerase domains and on the common functions of the subdomains. The classic polymerase domain is often compared in shape to a partially closed right hand (70), with the thumb, palm, and fingers representing subdomains.

The palm subdomain is the catalytic portion of the polymerase. Three carboxylate side chains are key to this active site. These residues are postulated to bind two metal ions $\left(\mathrm{Mg}^{++}\right)$that play critical roles in the catalytic step (47, 82 ). The polymerase catalyzes a phosphoryl transfer reaction in which the alpha phosphate of the incoming dNTP undergoes nucleophilic attack from the $\mathrm{OH}$ primer terminus. One metal ion may facilitate deprotonation of the $\mathrm{OH}$ terminus, while the other contributes to the formation of a transition state at the alpha phosphate of the dNTP. While the primary amino acid sequence varies among polymerases, the shape of active sites, especially the positions of the carboxylates, is superimposable (i.e., the shape is conserved among family $\mathrm{A}$ and B polymerases, as well as reverse transcriptases) $(47,52,80,83,104)$. The similarity of the palm active sites between RNA polymerases, DNA polymerases, and reverse transcriptases suggests that the mechanism by which the phosphoryl transfer reaction is catalyzed may be common to all polymerases. Even pol $\beta$, which shows little sequence identity to the other classes of polymerases, has equivalently positioned carboxylates in the active site.

Relatively minor changes in sequence within this structural region can affect substrate specificity. A single residue change in pol I polymerases results in more than a thousand-fold in- 
crease in ddNTP incorporation (88), thus facilitating chain termination sequencing. Single amino acid substitutions in pol I Klenow, $\phi 29$, and Vent (Thermococcus litoralis) DNA polymerase allow significant increase in ribonucleotide incorporation $(5,15,36)$, although these same changes do not improve the polymerase's ability to extend from a ribonucleotide at the $3^{\prime}$ end. A recent work (72) describes point mutations in Taq DNA polymerase that allow for the incorporation of successive ribonucleotides.

The thumb domains are less conserved but have the common feature of having largely helical structures (47). The thumb is believed to interact with the minor grove and also with the incoming nucleotide.

The finger subdomain shows the greatest structural diversity of the three polymerase subdomains. The finger domain of Klenow is mainly $\alpha$ helices, while that of HIV-RT has a higher content of $\beta$ strands. The finger domain may play a role in template fixation and template specificity; like the thumb, it is likely to interact with the incoming nucleotide.

An alignment of all types of polymerases reveals two motifs, $\mathrm{A}$ and $\mathrm{C}$ (not to be confused with the families described above), which are conserved among DNA-dependent RNA and DNA polymerases, as well as RNA-dependent DNA and RNA polymerases (23). A third motif, found in the finger sub-domain, is associated only with the DNA-dependent polymerases $(23,47)$. This is consistent with the idea that the palm contains a catalytic activity that is universal to all polymerases and that, while the fingers may also have a universal role in template binding, this subdomain is structurally adapted to the specific template involved (47).

\section{ACTIVITIES OF DNA POLYMERASES AND THEIR APPLICATIONS}

\section{$3^{\prime} \rightarrow 5^{\prime}$ Exonuclease Proofreading Activity-Fidelity for PCR}

Dozens of DNA polymerases have been cloned from organisms that grow at high temperatures. These include family A polymerases from thermophilic and hyperthermophilic bacteria, such as those from Thermus aquaticus, Thermus thermophilus, Thermus flavus, Thermotoga maritima, Bacillus strearothermophilus, and Bacillus caldotenax, as well as family B polymerases from Archaea such as Thermococcus litoralis, Thermococcus sp. $9^{\circ} \mathrm{N}$, Pyrococcus furiosus, and Pyrococcus woesei. Like their well-studied mesophilic counterparts, the thermostable polymerases characterized for PCR applications also contain either $5^{\prime} \rightarrow 3^{\prime}$ exonuclease activity, $3^{\prime} \rightarrow 5^{\prime}$ exo- nuclease activity, or both in addition to polymerase activity. Protein sequence alignments suggest that the $3^{\prime} \rightarrow 5^{\prime}$ exonuclease active site is highly conserved in all polymerases with this editing function $(45,46)$; however, the spatial relationship between this activity and the polymerase active site is less well understood. The spatial separation of this activity from the polymerase function is also widely variable, with $E$. coli DNA polymerase I activities separated by $25-30 \AA$, while in the family B polymerases such as $\phi 29$, the activities located in the binding cleft are separated by a single nucleotide (26). The two active sites may be functionally interdependent, as in the case of $P f u$ DNA polymerase (53), or actually share com mon residues such as $\phi 29$ (14). It is interesting to note that while the important active site residues are highly conserved, the rest of the protein scaffold within this region is divergent. There is currently little understanding of the mechanism involved in the switching of the primer strand between the polymerase and the $3^{\prime} \rightarrow 5^{\prime}$ exonuclease sites. Efforts have been made to identify possible residues involved in this transfer for $\phi 29$ (97) and in T4 $(6,84)$, but these residues or a suggested new motif (97) have not be identified in other related DNA polymerases (26).

The $3^{\prime} \rightarrow 5^{\prime}$ exonuclease activity associated with many polymerases conveys proofreading capability, which enhances polymerase fidelity, expressed as proportion of misincorporation. Reported fidelity ranges between $10^{-4}$ and $10^{-6}$ for the thermostable polymerases. There have been substantial differences between reported values, due in part to the influence of factors including primer-template combination, temperature, and ion effects $(54,93)$.

The fidelity is a function of the rates of the polymerase and exonuclease activities, which may be influenced by the rate of dissociation, the rate of conformational change before catalysis in the presence of mismatched primer terminus, and the rate of polymerization after misincorporation. The relationship between the $3^{\prime} \rightarrow 5^{\prime}$ exonuclease activity and polymerization rate can be described as a partitioning of the primertemplate between the two active sites. Switching between these sites is controlled in part by the dNTP concentration, although there is only partial suppression of proofreading in the presence of high dNTP concentrations; a phenomenon referred to as the "next-nucleotide effect" $(21,28,31,39)$. The competition between polymerization and proofreading is related to many factors, including increased rate of dissociation of mismatched dNTPs, decreased polymerization rate, ability of the enzyme to assume the correct conformation in presence of mismatch at $3^{\prime}$ terminus, and melting of the primer terminus in preparation for excision $(38,73)$.

The roles that sequence and structure of the template play have also been investigated (96). The DNA sequence of the primer terminus results in observed mutational hotspots. These hotspots are a reflection of local DNA stability in which stable DNA is less easily melted out to the single-stranded form required for $3^{\prime} \rightarrow 5^{\prime}$ exonuclease activity.

Selected applications require gene copies with a minimum of errors. The error rates in polymerases lacking $3^{\prime} \rightarrow 5^{\prime}$ exonuclease activity, such as Taq DNA polymerase of $1-2 \times 10^{-4}(73)$, can be sufficiently high that $20 \%-40 \%$ of the amplification products of a 200bp PCR product will contain mutations after 20 cycles $(18,58)$. Pfu and $T l i$ DNA polymerases, with their associated $3^{\prime} \rightarrow 5^{\prime}$ activity, have found heavy use in applications requiring high fidelity. Although these enzymes may extend a misincorporated nucleotide, they may correct the error up to five nucleotides after the misincorporation (38). This can also result in higher PCR yields because non-proofreading enzymes such as Taq DNA polymerase may fail to extend $3^{\prime}$ termini with mismatches, result- 
ing in non-participation of these fragments in further cycles of extension.

Circumstances that favor proofreading can, depending on the enzyme, correct $95 \%-99.5 \%$ of single-base substitution errors (32) but comes at the cost of increased removal of correct nucleotides (32) and hence a reduced net extension rate (93). Another drawback to the use of enzymes harboring this activity is the degradation of singlestranded primers by the $3^{\prime} \rightarrow 5^{\prime}$ exonuclease activity. Unannealed primers can be degraded, thereby reducing the num ber and rate of successful initiations, and could also remove intended mismatches near the $3^{\prime}$ end of the primer that were intended to generate mutations. By paying careful attention to the biochemical characteristics of the polymerases, proofreading enzymes have been used to generate PCR products of approximately $10 \mathrm{~kb}$ (54). However, products of $20-40 \mathrm{~kb}$, which are defined as long PCR products, require a more refined approach. It was suggested that the errors that could occur approximately every few kilobases (depending on the error rate of the polymerase) were constantly removing template from the extension pool before the synthesis of the full-length product (9). To achieve long PCR and maximize fidelity, a mixture of polymerases with different activities has proven effective. By using a small amount of proofreading polymerase in conjunction with a non-proofreading enzyme such as Taq DNA polymerase, long PCR yields were optimized $(9,18,20)$. In this way, primer degradation was minimized, more stringent annealing conditions were realized, and the proofreading function of the minority polymerase removed mismatched nucleotides.

\section{$5^{\prime} \rightarrow 3^{\prime}$ Exonuclease for Labeling and Detection of Sequences}

The $5^{\prime} \rightarrow 3^{\prime}$ exonuclease activity of E. coli DNA polymerase I has long been used to label DNA by nick translation. In this application, DNA polymerase binds to a nick in the doublestranded substrate. These occur in vivo during lagging strand synthesis of replication or upon removal of RNA primers from Okazaki fragments. If nicks are present, the polymerase function will add nucleotides to the template, while the $5^{\prime} \rightarrow 3^{\prime}$ exonuclease will concurrently remove nucleotides ahead of the polymerase. In vitro, this reaction has been harnessed by adding labeled nucleotides into the reaction mixture, such that radioactive, biotinylated, or fluorescent nucleotides become incorporated into the DNA.

The same domain that is responsible for $5^{\prime} \rightarrow 3^{\prime}$ exonuclease has been shown also to have structure-specific endonucleolytic activity. In this reaction, strands that have been displaced can be cleaved (61). Applications were noted in Lyamichev et al. (62), such as the ability to create cleavage reactions at a desired sequence. This is the basis for the Invader method of sequence detection (63) and mutation detection by fragment length polymorphism (69).

Structure-specific cleavage is the basis for the TaqMan ${ }^{\mathrm{TM}}$ assay (Roche Molecular Systems, Alameda, CA, USA). This mode of sequence detection involves binding of an oligonucleotide probe with both a reporter fluor and a quencher present (57). When a DNA polymerase synthesizing in the $5^{\prime} \rightarrow 3^{\prime}$ direction encounters such a bound oligonucleotide, strand displacement of the oligonucleotide begins, followed by cleavage of the displaced end, resulting in the liberation of the detection fluor from its quencher. This activity involves a combination of strand displacement, followed by cleavage (41) via the $5^{\prime} \rightarrow 3^{\prime}$ structure-specific endonuclease. Mutations that inactivate this activity are described below.

\section{Polymerases for DNA Sequencing}

Chain termination sequencing (76) relies on the polymerase function, initiating at specific primers. Dideoxynucleotides are used to terminate synthesis prematurely so that a collection of sequence-specific fragments differing in length is generated. Labels for the detection of the DNA fragments can be present on the primer or on the terminators, posing a challenge to the polymerase to incorporate these unusual substrates. Incorporation efficiency of the dideoxynucleotides is a vital consideration in selecting a polymerase as a sequencing enzyme. In addition, the 
Table 1. Classification and Characteristics of Widely Used DNA Polymerases

\begin{tabular}{|c|c|c|c|c|c|c|}
\hline Enzyme & Family & $\begin{array}{l}3^{\prime} \rightarrow 5^{\prime} \\
\text { Exo }\end{array}$ & $\begin{array}{l}5^{\prime} \rightarrow 3^{\prime} \\
\text { Exo }\end{array}$ & $\begin{array}{c}\text { Reverse } \\
\text { Transcription }\end{array}$ & $\begin{array}{c}\text { Strand } \\
\text { Displacement }\end{array}$ & References \\
\hline Bacillus stearothermophilus pol I & A & - & + & & + & $4,16,65,74$ \\
\hline E. colipol I & A & + & + & + & + & $11,16,48,55$ \\
\hline Exonuclease free Klenow & A & + & + & & & 51,102 \\
\hline Klenow & A & + & - & & + & 51,102 \\
\hline Mitochondrial pol gamma & A & + & & & & 16,34 \\
\hline $\begin{array}{l}\text { Thermoanaerobacter } \\
\text { thermohydrosulfuricus pol I }\end{array}$ & A & - & + & + & + & 64 \\
\hline T5 & A & & - & & & 16,77 \\
\hline T7 & A & + & - & & & $16,49,90,92$ \\
\hline Thermus aquaticus pol I & A & - & + & & & $8,16,100$ \\
\hline Thermus flavus pol I & A & & + & & & $3,16,40$ \\
\hline Thermus thermophilus DNA polymerase & A & & & + & & 66 \\
\hline Bacteriophage phi 29 & B & + & + & & + & $13,14,16,26,55,79$ \\
\hline Bacteriophage T4 & B & + & - & & - & $6,16,17,42,54,84$ \\
\hline E. coli pol II & B & + & - & & - & $16,17,45,55$ \\
\hline Eukaryotic pol $\delta$ & B & + & & & & 16,78 \\
\hline Eukaryotic pol $\varepsilon$ & B & + & & & & 16,44 \\
\hline Pyrococcus furiosus DNA pol & B & + & & & & 16,53 \\
\hline Pyrococcus sp. Strain KOD1 & B & + & - & & & 93 \\
\hline Pyrococcus woesei DNA pol & B & + & & & & $16,53,73,93$ \\
\hline Eukaryotic $p o / \alpha$ & B & & & & & 12,16 \\
\hline Thermococcus litoralis & B & + & - & & + & 16,54 \\
\hline Thermococcus sp. $9^{\circ} \mathrm{N}$ & B & + & & & & 81 \\
\hline Bacillus subtilus pol III & C & + & & & & 10,16 \\
\hline E. colipol III & C & + & - & & $+(\mathrm{HE}+\mathrm{SSB})$ & $16,17,55$ \\
\hline Eukaryotic DNA pol $\beta$ & $x$ & - & - & & & $1,71,85-87$ \\
\hline Moloney murine leukemia virus $\mathrm{RT}$ & & & & + & + & 56,105 \\
\hline
\end{tabular}

ideal sequencing enzyme should be free of $5^{\prime} \rightarrow 3^{\prime}$ as well as $3^{\prime} \rightarrow 5^{\prime}$ exonuclease activities.

The $5^{\prime} \rightarrow 3^{\prime}$ nuclease activity is detrimental to sequencing, whether the label for detection is on the $5^{\prime}$ end of the sequencing fragment, incorporated into the fragment as an internal label, or is on the terminator. Primer labels could be removed by the $5^{\prime} \rightarrow 3^{\prime}$ exonuclease activity whenever a primer or nascent sequencing fragment is annealed to the template, impairing detection of the fragments. Endonucleolytic cleavage will shorten the sequencing fragment; these fragments will go undetected if only the $5^{\prime}$ end of the primer is labeled. However, if the label is internal or on the terminators, this reaction will lead to labeled fragments of varying size, contributing to background noise. To interpret a sequencing ladder correctly, all fragments must have the same $5^{\prime}$ end, beginning with the first nucleotide of the primer, and terminating with a dideoxynucleotide.

In some cases, the domain of the polymerase that has $5^{\prime} \rightarrow 3^{\prime}$ exonuclease activity is absent, as in the case of T7 Sequenase ${ }^{\mathrm{TM}}$ DNA polymerase (Amersham Pharmacia Biotech, Piscataway, NJ, USA) (92). The domain on which this activity resides can be removed by protease cleavage, as first demonstrated by Klenow with $E$. coli DNA polymerase I (51), or by deletion 
as in Thermo Sequenase ${ }^{\mathrm{TM}}$ polymerase (Amersham Pharmacia Biotech) (100). Alternatively, point mutations can be introduced into the enzyme, which inactivate this activity. There are conserved regions in the $5^{\prime} \rightarrow 3^{\prime}$ exonuclease domain (40), and mutations in these residues can lead to the inactivation of the $5^{\prime} \rightarrow 3^{\prime}$ exonuclease activity, as in Thermo Sequenase II ${ }^{\mathrm{TM}}$ DNA polymerase (Amersham Pharmacia Biotech). Other mutations such as Taq G46D lie outside of these conserved regions (2), and this mutation is found in Amplitaq FS ${ }^{\mathrm{TM}}$ DNA polymerase (Roche Molecular Biochemicals, Indianapolis, IN, USA). Removal of the $5^{\prime} \rightarrow 3^{\prime}$ exonuclease activity can have other consequences for DNA sequencing. In some cases, enzymes with deletions have also suffered losses in processivity. On the other hand, in the case of Taq DNA polymerases with aminoterminal deletions, some of these enzymes enjoy greater thermostability than the full-length enzymes (100), as well as greater fidelity (8). Thermostability is critical for cycle sequencing, in which the reaction temperature is cycled to obtain a linear amplification of the sequencing products. Greater thermostability permits longer enzyme survival under these conditions, which leads to greater sensitivity and im proved signal strength.

While $3^{\prime} \rightarrow 5^{\prime}$ exonuclease activity has utility for PCR, this activity is not desirable in sequencing enzymes. As described above, errors in PCR can be amplified, whereas those in a sequencing reaction are not, because the fragments generated do not serve as templates in subsequent rounds. Misincorporations in sequencing reactions are silent, unless the fragment is erroneously terminated with the incorrect ddNTP. In the latter case, the vast majority of fragments will be correctly terminated, and the misincorporation will still go undetected. The $3^{\prime} \rightarrow 5^{\prime}$ exonuclease prefers the unpaired $3^{\prime}$ terminus of ssDNA as a substrate or the unpaired (mispaired) $3^{\prime}$ terminus of dsDNA. While removal of the occasional mispaired nucleotide may seem a benefit, this is outweighed for sequencing by the reduced rate of polymerization in the presence of the proofreading activity. The $3^{\prime} \rightarrow 5^{\prime}$ exonuclease activity is detri- mental to sequencing by hydrolyzing single-stranded sequencing primers.

Conserved regions that are immediately upstream from the polymerase domain encode the $3^{\prime} \rightarrow 5^{\prime}$ exonuclease activity. This activity cannot be removed by deletion of this domain because large deletions from this region of the enzyme cause inactivation of the polymerase activity as well. Point mutations and small deletions have been identified that inactivate the $3^{\prime} \rightarrow 5^{\prime}$ exonuclease activity, as has been done with T7 (90). Some type I DNA polymerases, such as those derived from Thermus aquaticus and Thermus thermophilus lack this activity, as the conserved motifs are not present in these enzymes. Derbyshire et al. (24) have reviewed conserved motifs and the effects of mutations therein.

The exonuclease activities are detrimental to chain termination DNA sequencing; however, there are several other qualities that enhance the performance of a sequencing enzyme. The ability to incorporate chain terminators, such as ddNTPs, is critical for the Sanger sequencing method (75). Most polymerases naturally discriminate against ddNTPs_-given a mixture of the natural substrate dNTPs and ddNTPs at equal concentration, these enzymes will incorporate very little ddNTP. T7 DNA polymerase, which is a family A enzyme that readily incorporates ddNTPs (92), is a naturally occurring exception to this rule. Other enzymes used for sequencing, such as Klenow fragment, require a much higher ratio of ddNTP to dNTP concentration for sequencing. There is a correlation between discrimination against ddNTPs and uneven signal intensity in sequencing bands, which is characteristic of enzymes like Klenow but not of T7 Sequenase $(35,91)$. Tabor and Richardson (88) explored the basis for the discrimination against ddNTPs as substrates. They discovered, by swapping motifs in the T7 enzyme with those in E. coli pol I and Taq DNA polymerase, that a single amino acid residue is responsible for discrimination against nucleotides lacking a 3' hydroxyl in the sugar moiety. When a tyrosine (Y) residue on the O-helix of T7 polymerase was introduced into the corresponding position to replace the phenylalanine (F) residue of E. coli pol
I and Taq DNA polymerase, it was found that these engineered enzymes no longer discriminated against ddNTP incorporation. This mutation has subsequently been introduced into an exonuclease-free version of Taq DNA polymerase, is marketed as Thermo Sequenase polymerase, and is also the basis of the Amplitaq FS sequencing enzyme. Uniformity of signal is also crucial to detection of heterozygotes or other mixed template sequences. Polymerases with the FY mutation have allowed for heterozygote and mutation detection $(19,100)$.

Polymerization is a reversible reaction; pyrophosphate, a product of polymerization, is a substrate for the reverse reaction of pyrophosphorolysis. Pyrophosphorolysis can occur when substrate becomes limiting. Pyrophosphatase is therefore included in formulations for enzymes, which easily incorporate the terminators, thereby removing pyrophosphate from the reaction. Without pyrophosphatase, these enzymes can just as easily remove the terminators (89).

It is interesting to note that the $\mathrm{Y}$ residue in the O-helix is found in a motif that is conserved throughout all of the DNA-dependent polymerase families. However, at the exact position of the $\mathrm{Y}$ residue in $\mathrm{T} 7$, there is no corresponding residue in family $\mathrm{B}$ polymerases. Various groups have tried to improve the ddNTP incorporation by family B polymerases using mutagenesis, both site specific and random (29, 36). Modest success was attained, in that the incorporation of ddNTPs was improved 15-fold in the case of Vent ${ }^{\mathrm{TM}}$ DNA polymerase (New England Biolabs, Beverly, MA, USA) (36) and 150fold in the case of Pyrococcus furiosus DNA polymerase (29). However, neither of these enzymes approaches the facility of ddNTP incorporation or the uniform signal intensity of members of the pol I family that have a tyrosine residue in the O-helix. Tabor and Richardson (88) achieved greater than 1000fold improvement in the incorporation of ddNTPs by three members of the DNA pol I family.

Thermostability is desirable in a sequencing enzyme if a cycle sequencing protocol is utilized, in which reaction temperature is cycled as in PCR. In this way, the template is reused in every cy- 
cle, providing a linear amplification of sequencing products. Among the type I polymerases, members of the Thermus family have been used as cycle sequencing enzymes because of their thermostability. Greater thermostability allows more cycles to be performed and, hence, greater sensitivity to low amounts of template. Indeed, using Thermo Sequenase polymerase and $33 \mathrm{P}$ terminators, sufficient sensitivity is achievable to sequence directly from total chromosomal DNA from bacterial and yeast genomes, without cloning (30). Certain members of family B have even greater thermostability (i.e., those from the hyperthermophilic Archaea, such as Pyrococcus furiosus and Thermococcus litoralis). While the greater thermostability of family B enzymes holds the promise of direct sequencing from even larger genomes, their discrimination against ddNTPs is still too high for this to be practical for applications requiring the highest sensitivity. Some family B enzymes are currently used for cycle sequencing of cloned DNAs.

Further improvements in cycle sequencing have been achieved through the introduction of Thermo Sequenase II polymerase. This DNA polymerase is an exonuclease-free, full-length, thermostable enzyme that features improvements in salt tolerance and signal uniformity with dye-labeled terminators. Variations in salt tolerance and incorporation of dye terminators are found among different polymerases, and the molecular mechanisms for these differences are currently under investigation. Salt tolerance is favorable when the quality of template is variable because of salt carryover from sample preparation. Improved signal uniformity allows for greater accuracy of base calling, permitting longer read lengths, and better detection of mixed template sequences.

\section{Strand Displacement}

The recent advances in the ability to detect minute levels of infectious agents or to interrogate genomic DNA for rare mutations have been driven by nucleic acid amplification technologies. The majority of these diagnostic and detection methods use PCR-based thermal cycling techniques. However, methods such as strand displacement amplification (103) and rolling circle amplification $(33,59)$ have further stim. ulated new isothermal amplification methods. The advent of new methods puts new demands for another group of enzymes with specific properties different from those required for sequencing or PCR applications.

Strand displacement activity is a striking feature of some family A and B polymerases. This activity involves the unwinding of duplex DNA in the path of the advancing polymerase with no need for added protein co-factors such as helicases or single-strand binding proteins. Strand displacement activity has been studied by using two adjacent primers annealed to the template strand. When a polymerase reaches the $5^{\prime}$ end of the second or blocking primer, there are three possibilities: (i) polymerization stops, (ii) the primer ahead of polymerization is degraded by the $5^{\prime} \rightarrow 3^{\prime}$ exonuclease activity, or (iii) the primer-template duplex in the path of polymerization is unwound and displaced as ssDNA, allowing polymerization to continue.

A unique aspect of strand displacement activity was revealed in temperature studies with $T l i$ (Vent) polymerase (54). Here, it was revealed that there was polymerase activity, but no strand displacement activity at $55^{\circ} \mathrm{C}$; the strand displacement activity increased with temperature through $72^{\circ} \mathrm{C}$. An exonuclease-free mutant of the same enzyme also showed this apparent duality of temperature dependence for polymerase and strand displacement activity, although in this case the enzyme did not completely lose strand displacement activity at lower temperatures (54). Similar observations of temperature-dependent strand displacement activity were made for Deep Vent ${ }^{\mathrm{TM}}$ (New England Biolabs) polymerase and exonuclease-free $P f u$ DNA polymerase, in which strand displacement activity was not observed below $70^{\circ} \mathrm{C}$, even though polymerization was functional at these temperatures (54). On the other hand, $B s t$ and $B c a$ DNA polymerases performed strand displacement at all temperatures tested (73). These differences in temperature optima between polymerase activity and strand displacement activity may reflect temperature-dependent conformational issues or suggest that the activities may not be directly coupled within a single active site for all polymerases.

Localization of the intrinsic strand displacement activity has been attempted for a few enzymes. Specific mutagenesis studies with the Bacillus subtilis phage polymerase $\phi 29$ revealed that the strand displacement activity of that polymerase was reduced when mutations were introduced into the $3^{\prime} \rightarrow 5^{\prime}$ exonuclease active site (79). In that specific case, replacement of a highly conserved aspartic acid residue in the $3^{\prime} \rightarrow 5^{\prime}$ exonuclease domain inactivated the exonuclease activity and drastically decreased strand displacement activity. These authors suggested that the strand displacement activity resides in the Nterminal domain and overlaps the $3^{\prime} \rightarrow 5^{\prime}$ exonuclease domain (79). How ever, these results may not represent a general trend because work done with exonuclease-free versions of Vent ${ }^{\mathrm{TM}}$ DNA polymerase, $P f u$ DNA polymerase, and Klenow fragment suggest that even complete removal of the $3^{\prime} \rightarrow 5^{\prime}$ activity does not remove the intrinsic strand displacement activity in any of these enzymes $(25,73)$. Clearly, there is at present no consensus as to the exact motifs or even domains in which this activity is localized.

The rolling circle replication mechanism used by viruses with circular genomes or plasmids illuminated many aspects of strand displacement activity in vivo. Rolling circle replication generates a single-stranded product that has many tandem copies of the complement of the circular template. This replication method inspired a number of new amplification techniques that distinguish themselves from PCR in that they are isothermal processes and rely on polymerases that have strong strand displacement activity.

One of the first embodiments of this is strand displacement amplification (102). The method uses intrinsic activities of restriction enzymes and exonuclease-free Klenow, which is devoid of $5^{\prime} \rightarrow 3^{\prime}$ and $3^{\prime} \rightarrow 5^{\prime}$ exonuclease activity. This enzyme could neither degrade single-stranded primers in solution nor degrade annealed primers in the path of polymerization. The amplification also relies on the fact that restriction enzymes, such as HincII, cannot cut phos- 
phorothioate linkages. Hence, synthesis of a recognition site with dATP $\alpha \mathrm{S}$ in one strand means that only the opposite strand (template) will be cleaved to generate a nick. The nick serves as the start for strand displacement. The am plification begins when displaced primer strand anneals with added template strand oligonucleotides and displaced template strand anneals with added primer strand oligonucleotides. New nicks are generated, and the extension of the oligonucleotide primers at the nicks results in more displaced strands that again act as targets for additional nicking and strand displacement activity, ultimately resulting in up to $10^{7}$-fold amplification (103).

Rolling circle amplification (RCA) is another novel isothermal amplification method. In this case, a primer is annealed to a single-stranded circular tem plate and extended with a polymerase that has strong strand displacement activity to generate long tandem repeat copies of the original template $(33,59)$. This so-called linear RCA with M13 template has yielded impressive results when $\phi 29$ polymerase is used. $\phi 29$ has extremely high processivity greater than $70 \mathrm{~kb}$ (13) and is capable of catalyzing production of linear product of $\geq 23 \mathrm{~kb}$ in $10 \mathrm{~min}$ (60). In similar assays, others have shown that the amplification continues in a linear fashion with a half-life of $11 \mathrm{~h} \mathrm{(7).} \mathrm{The} \mathrm{combination} \mathrm{of} \mathrm{strong}$ sequence-independent and temperatureindependent strand displacement activity and the extreme processivity of $\phi 29$ makes the production of amplification products in the $400-500 \mathrm{~kb}$ size range possible (7). If a unique restriction site is present in the original circular template, then the linear product can be efficiently collapsed to one band with restriction digestion, using a complementary oligonucleotide to form the double-stranded restriction site (95).

Single-stranded circular templates for RCA can also be generated in situ. A single linear oligonucleotide is designed such that the $5^{\prime}$ and $3^{\prime}$ regions will base pair next to each other on the linear target strand. Ligation generates a closed circular oligonucleotide or socalled padlock probes that is catenated to the target sequence $(60,67)$. The ligated probe can then be utilized for RCA amplification. Since ligases discrimi- nate strongly between matched and mismatched annealed ends of the probe nucleotide, the method can be used to score genetic mutations $(60,68,95)$.

Exponential amplification is also possible with the inclusion of a second primer that binds to the complement sequence of the original circular template. The reaction begins with the generation of linear tandem copies, then the second primer anneals and is extended by polymerase, making the linear product double-stranded. The ensuing strand displacement regenerates multiple binding sites where both primers can anneal. The result is a continuously expanding collection of branched DNA or hyperbranched DNA product connected to the original circle (60). The strand displacement also generates a discrete set of free dsDNA fragments corresponding to the unit length of the circle. The suitable subset of enzymes for this application with the appropriate strand displacement activity expands when circles of $150 \mathrm{bp}$ or less are used $(33,59)$. In this case, the torsional strain on the duplex product generated as the enzyme proceeds around the circle is such that the second strand is prone to peel away on its own. The result of this hyperbranched or cascade rolling circle method is a $10^{9}$-fold amplification in less than 90 min (60). Coupled to fluorescence detection methods (95), this exciting amplification technology will certainly find use in detection of point mutations in many genomic DNA applications, including the human genome.

\section{Reverse Transcription}

Several family A DNA-dependent DNA polymerases, including E. coli DNA polymerase I (48), Thermus thermophilus polymerase (66), and the pol I DNA polymerase of Thermoanearobacter thermohydrosulfuricus (Tts) (64), have been shown to have reverse transcriptase activity (i.e., RNA-dependent DNA polymerase activity) under certain conditions. One application of such an enzyme is RT-PCR, in which an RNA template is used to generate a cDNA, which is amplified by PCR. Thermostable DNA-dependent DNA polymerases that can also use RNA templates, such as $T$ th DNA polymerase, allow RTPCR to be carried out by a single en- 
zyme. The reactions can be done in a single tube with fewer manipulations than are required for the traditional process.

A second application of these family A polymerases may be as tools for cDNA synthesis or cDNA labeling applications. Family A polymerases may offer several advantages over viral reverse transcriptases for these applications. First, viral reverse transcriptases have an associated RNase $\mathrm{H}$ activity. This endonuclease activity may degrade the RNA template during cDNA synthesis, resulting in truncated products (56). While the family A polymerases have $5^{\prime} \rightarrow 3^{\prime}$ exonuclease activity that will degrade RNA primers associated with lagging strand synthesis, this RNase $\mathrm{H}$ activity does not, by its nature, interfere with cDNA synthesis.

The thermostable family A DNA polymerases may provide additional advantages over the use of mesophilic RT enzymes such as those from Moloney murine leukemia virus (MMLV) and avian myeloblastosis virus (AMV). Conceivably, the higher reaction temperature may allow for melting of the RNA template, resulting in better read through of secondary structure in the mRNA. The RNase $\mathrm{H}$ activity has been removed from engineered versions of MMLV RT (56), and this is the enzyme that is currently most widely used for cDNA applications.

Potential enzymes must be evaluated with the specific application in mind. For example, cDNA synthesis performed for the purpose of cloning must yield full-length product. In contrast, cDNA synthesis is often performed to make labeled cDNA probes that can then be applied to fixed arrays and evaluated for gene expression. Full-length probes are not required for this application, and, in fact, shorter products may be desirable. These applications place premiums on different polymerase properties, and it is likely that no single polymerase will be best for all applications.

\section{CONCLUSION}

DNA polymerases have proven to be versatile tools in the molecular biology laboratory. They have been used to prepare DNA for cloning, to label DNA for detection, to amplify DNA, to de- tect specific sequences, and to determine the sequence of genomes up to the size of the complete human genome. Among these applications, uses have emerged for polymerases with and without exonucleases. Similarly, uses have emerged for highly thermostable polymerases and for those that are not. Future applications are expected to take further advantage of this remarkable and versatile enzyme, perhaps in re-sequencing the places where the genomes of individuals differ or in further manipulating DNA for use in genetic investigations and alterations or therapy. There is little doubt that new and unanticipated applications of this enzyme will emerge as new polymerases and mutations of polymerases are created and characterized.

\section{ACKNOWLEDGMENTS}

The authors wish to thank Drs. Carl Fuller and Tony Murray for critical reading of the manuscript and many helpful suggestions.

\section{REFERENCES}

1.Abbotts, J., D.N. SenGupta, B. Zmudzka, S.G. Widen, V. Notario, and S.H. Wilson. 1988. Expression of human DNA polymerase beta in Escherichia coli and characterization of the recombinant enzyme. Biochemistry 27 : 901-909.

2.Abramson, R.D. and D.H. Gelfand. 1995. 5' to $3^{\prime}$ exonuclease mutations of thermostable DNA polymerases. US Patent 5466591 . Hoffman LaRoche, Inc., assignee.

3.Akhmetzjanov, A.A. and V.A. Vakhitov. 1992. Molecular cloning and nucleotide sequence of the DNA polymerase gene from Thermus flavus. Nucleic Acids Res. 20:5839.

4.Aliotta, J.M., J.J. Pelletier, J.L. Ware, L.S. Moran, J.S. Benner, and H. Kong. 1996. Thermostable Bst DNA polymerase I lacks a 3' to $5^{\prime}$ proofreading exonuclease activity. Genet. Anal. 12:185-195.

5.Astatke, M., K. Ng, N.D.F. Gridley, and C. Joyce. 1998. A single side chain prevents $E$. coli DNA polymerase I (Klenow fragment) from incorporating ribonucleotides. Proc. Natl. Acad. Sci. USA 95:3402-3407.

6.Baker, R.P. and L.J. Reha-Krantz. 1998. Identification of a transient excision intermediate at the crossroads between DNA polymerase extension and proofreading pathways. Proc. Natl. Acad. Sci. USA 95:3507-3512.

7.Baner, J., M. Nilsson, M. Mendel-Hartvig, and U. Landegren. 1998. Signal amplification of padlock probes by rolling circle replication. Nucleic Acids Res. 26:5073-5078.
8.Barnes, W.M. 1992. The fidelity of Taq polymerase catalyzing PCR is improved by an Nterminal deletion. Gene 112:29-35.

9.Barnes, W.M. 1994. PCR amplification of up to $35-\mathrm{kb}$ DNA with high fidelity and high yield from lambda bacteriophage templates. Proc. Natl. Acad. Sci. USA 91:2216-2220.

10.Barnes, M.H., R.A. Hammond, C.C. Kennedy, S.L. Mack, and N.C. Brown. 1992. Localization of the exonuclease and polymerase domains of Bacillus subtilis DNA polymerase III. Gene 111:43-49.

11.Beese, L.S. and T.A. Steitz. 1991 . Structural basis for the $3^{\prime}$ to $5^{\prime}$ exonuclease activity of $E s$ cherichia coli DNA polymerase I: a two metal ion mechanism. EMBO J. 1:25-33.

12.Bernad, A., A. Zaballos, M. Salas, and L. Blanco. 1987. Structural and functional relationships between prokaryotic and eukaryotic DNA polymerases. EMBO J. 6:4219-4225.

13. Blanco, L., A. Bernad, J.M. Lazaro, G. Martin, C. Garmendia, and M. Salas. 1989. Highly efficient DNA synthesis by the phage 29 DNA polymerase. Symmetrical mode of DNA replication. J. Biol. Chem. 264:89358940.

14.Blanco, L. and M. Salas. 1995. Mutational analysis of bacteriophage $\$ 29$ DNA polymerase. Methods Enzymol. 262:283-294.

15.Bonnin, A., J.M. Lazaro, L. Blanco, and M. Salas. 1999. A single tyrosine prevents insertion of ribonucleotides in the eukaryotic-type ф29 DNA polymerase. J. Mol. Biol. 290:241251.

16.Braithwaite, D.K. and J. Ito. 1993. Compilation, alignment, and phylogenetic relationships of DNA polymerases. Nucleic Acids Res. 21:787-802.

17.Canceill, D., E. Viguera, and S. Dusko Ehrlich. 1999. Replication slippage of different DNA polymerases is inversely related to their strand displacement efficiency. J. Biol. Chem. 274:27481-27490.

18.Cha, R.S. and W.G. Thilly. 1993. Specificity, efficiency, and fidelity of PCR. PCR Methods Appl. 3:518-529.

19.Chadwick, R.B., M.P. Conrad, M.D. McGinnis, L. Johnston-Dow, S.L. Spurgeon, and M.N. Kronick. 1996. Heterozygote and mutation detection by direct automated fluorescent DNA sequencing using a mutant Taq polymerase. BioTechniques 20:676-683.

20.Cheng, S., C. Fockler, W.M. Barnes, and R. Higuchi. 1994. Effective amplification of long targets from cloned inserts and human genomic DNA. Proc. Natl. Acad. Sci. USA 91:56955699.

21.Clayton, L.K., M.F. Goodman, E.W. Branscomb, and D.J. Galas. 1979. Error induction and correction by mutant and wild type T4 DNA polymerases: kinetic error discrimination mechanisms. J. Biol. Chem. 254:19021912.

22.Cramer, P., D.A. Bushnell, J. Fu, A.L. Gnatt, B. Maier-Davis, N.E. Thompson, R.R. Burgess, A.M. Edwards, P.R. David, and R.D. Kornberg. 2000. Architecture of RNA polymerase II and implications for the transcription mechanism. Science 288:640-649.

23.Delarue, M., O. Poch, N. Tordo, D. Moras, and P. Argos. 1990. An attempt to unify the structure of polymerases. Protein Eng. 3:461- 
467.

24.Derbyshire, V., J.K. Pinsonneault, and C.M. Joyce. 1995. Structure-function analysis of 3 to $5^{\prime}$ exonuclease of DNA polymerases. Methods Enzymol. 262:363-385.

25.Derbyshire, V., P.S. Freemont, M.R. Sanderson, L. Beese, J.M. Friedman, C.M. Joyce, and T.A. Steitz. 1988. Genetic and crystallographic studies of the $3^{\prime}, 5^{\prime}$-exonucleolytic site of DNA polymerase I. Science 240:199-201.

26.De Vega, M., L. Blanco, and M. Salas. 1999. Processive proofreading and the spatial relationship between polymerase and exonuclease active sites of bacteriophage $\Phi 29$ DNA polymerase. J. Mol. Biol. 292:39-51.

27.Doublie, S., S. Tabor, A. Long, C. Richardson, and T. Ellenberger. 1998. Crystal Structure of a bacteriophage T7 DNA replication complex at 2.2A resolution. Nature 391:251258.

28.Echols, H. and M.F. Goodman. 1991. Fidelity mechanisms in DNA replication. Annu. Rev. Biochem. 60:477-511.

29.Evans, S.J., M.J. Fogg, A. Mamone, M. Davis, L.H. Pearl, and B.A. Connolly. 2000. Improving dideoxynucleotide-triphosphate utilisation by the hyper-thermophilic DNA polymerase from the archeon Pyrococcus furiosus. Nucleic Acids Res. 28:1059-1066.

30.Fan, J., R.S. Ranu, C. Smith, C. Ruan, and C.W. Fuller. 1996. DNA sequencing with $\{\alpha-33 P\}$-labeled ddNTP terminators: a new approach to DNA sequencing with Thermo Sequenase $^{\mathrm{TM}}$ DNA polymerase. BioTechniques 6:1132-1137.

31.Fersht, A.R. 1979. Fidelity of replication of phage $\phi X 174$ DNA by DNA polymerase III holoenzyme; spontaneous mutation by misincorporation. Proc. Natl. Acad. Sci. USA 76:4946-4950.

32.Fersht, A.R., J.W. Knill-Jones, and W.C. Tsui. 1982. Kinetic basis of spontaneous mutations, misinsertion frequencies, proofreading specificities, and cost of proofreading by DNA polymerases of Escherichia coli. J. Mol. Biol. 156:37-51.

33.Fire, A. and S.Q. Xu. 1997. Rolling replication of short DNA circles. Proc. Natl. Acad. Sci. US A92:4641-4645.

34.Foury, F. and S. Vanderstraeten. 1992. Yeast mitochondrial DNA mutators with deficient proofreading exonucleolytic activity. EMBO J. 11:2717-2726.

35.Fuller, C.W. 1989. Variations in Band Intensities in DNA Sequencing. Editorial Comments, United States Biochemical Corporation 16:1-8.

36. Gardner, A.F. and W.E. Jack. 1999. Determinants of nucleotide sugar recognition in an archeon DNA polymerase. Nucleic Acids Res. 27:2545-2553

37.Gerlach, V.L., L. Aravind, G. Gotway, R.A. Schultz, E.V. Koonin, and E.C. Freidberg 1999. Human and mouse homologs of Escherichia coli Din B (DNA polymerase IV), members of the UmuC/DinB superfamily. Proc. Natl. Acad. Sci. USA 96:11922-11927.

38.Goodman, M.F. and D.K. Fygenson. 1998. DNA polymerase fidelity: from genetics toward a biochemical understanding. Genetics 148:1475-1482.

39.Goodman, M.F., F.S. Creighton, L.B. Bloom, and J. Petruska. 1993. Biochemical basis of
DNA replication fidelity. Crit. Rev. Biochem. Mol. Biol. 28:83-126.

40.Gutman, P.D. and K.W. Minton. 1993. Conserved sites in the $5^{\prime}$ to $3^{\prime}$ exonuclease domain of Escherichia coli DNA polymerase. Nucleic Acids Res. 21:4406-4407.

41.Holland, P.M., R.D. Abramson, R. Watson, and D.H. Gelfand. 1991. Detection of specific PCR product by utilizing the $5^{\prime}$ to $3^{\prime}$ exonuclease activity of Taq DNA polymerase. Proc. Natl. Acad. Sci. USA 88:7276-7280.

42.Hollingsworth, H.C. and N.G. Nossal. 1991. Bacteriophage $\mathrm{T} 4$ encodes an RNase $\mathrm{H}$ which removes RNA primers made by the T4 DNA replication system in vitro. J. Biol. Chem. 266:1888-1897.

43.Huang, Y. and J. Ito. 1999. DNA polymerase $\mathrm{C}$ of the thermophilic bacterium Thermus aquaticus: classification and phylogenetic analysis of the family C DNA polymerases. J. Mol. Evol. 48:756-769.

44.Hubscher, U., H. Nasheuer, and J.E. Syvaoja. 2000. Eukaryotic DNA polymerases, a growing family. TIBS 25:143-147.

45. Ishino, Y., H. Iwasaki, I. Kato, and H. Shinagawa. 1994. Amino acid sequence motifs essential to $3^{\prime}$ to $5^{\prime}$ exonuclease activity of $E s$ cherichia coli DNA polymerase II. J. Biol. Chem. 269:14655-14660.

46.Joyce, C.M. and T.A. Steitz. 1994. Function and structure relationships in DNA polymerases. Annu. Rev. Biochem. 63:777-822.

47.Joyce, C.M. and T.A. Steitz. 1995. Polymerase structures and function: variations on a theme? J. Bacteriol. 177:6321-6329.

48.Karkas, J.D., J.G. Stavrianopoulos, and E. Chargaff. 1972. Action of DNA polymerase I of Escherichia coli with DNA-RNA hybrids as templates. Proc. Natl. Acad. Sci. USA 69:398402.

49.Kerr, C. and P.D. Sadowski. 1972. Gene 6 exonuclease of bacteriophage T7. I. Purification and properties of the enzyme. J. Biol. Chem. 247:305-310

50.Kiefer, J.R., C. Mao, J.C. Braman, and L.S. Beese. 1998. Visualising DNA replication in a catalytically active Bacillus DNA polymerase crystal. Nature 391:304-307.

51. Klenow, H. and I. Henningsen. 1970. Selective elimination of the exonuclease activity of the deoxyribonucleic acid polymerase from $E$. coli $\mathrm{B}$ by limited proteolysis. Proc. Natl. Acad. Sci. USA 65:168-175.

52.Kohlstaedt, L.A., J. Wang, J.M. Friedman, P.A. Rice, and T.A. Steitz. 1992. Crystal structure at 3.5A resolution of HIV-1 reverse transriptase complexed with an inhibitor. Science 256:1783-1790.

53.Komori, K. and Y. Ishino. 2000. Functional interdependence of DNA polymerizing and 3 to $5^{\prime}$ exonucleolytic activities in Pyrococcus furiosus DNA polymerase I. Protein Eng. 13:4147.

54.Kong, H., R.B. Kucera, and W.E. Jack. 1993. Characterization of a DNA polymerase from the hyperthermophile Archaea Thermococcus litoralis. J. Biol. Chem. 268:1965-1975.

55.Kornberg, A. and T.A. Baker. 1992. DNA Replication, 2nd ed. W.H. Freeman. New York, NY.

56.Kotewicz, M.L., C.M. Sampson, J.M. D'A lessio, and G.F. Gerard. 1988. Isolation of cloned Moloney murine leukemia virus reverse transcriptase lacking ribonuclease $\mathrm{H}$ activity. Nucleic Acids Res. 16:265-277.

57.Lee, L.G., C.R. Connell, and N. Block. 1993 Allelic discrimination by nick translation PCR with fluorogenic probes. Nucleic Acids Res. 21:3761-3766.

58.Ling, L.L., P. Keohavong, C. Dias, and W.G. Thilly. 1991. Optimization of the polymerase chain reaction with regard to fidelity: modified T7, Taq, and Vent DNA polymerases. PCR Methods Appl. 1:63-69.

59.Liu, D., S.L. Daubendiek, M.A. Zillman, K. Ryan, and E.T. Kool. 1996. Rolling circle DNA synthesis: small circular oligonucleotides as efficient templates for DNA polymerases. J. Am. Chem. Soc. 118:1587-1594.

60.Lizardi, P.M., X. Huang, Z. Zhu, P. BrayWard, D.C. Thomas, and D.C. Ward. 1998. Mutation detection and single-molecule counting using isothermal rolling-circle amplification. Nat. Genet. 19:225-232.

61.Lundquist, R.C. and B.M. Olivera. 1982. Transient generation of displaced single-stranded DNA during nick translation. Cell 31:53-60.

62.Lyamichev, V., M.A. Brow, and J.E. Dahlberg. 1993. Structure-specific endonucleolyti cleavage of nucleic acids by eubacterial DNA polymerases. Science 260:778-783.

63.Lyamichev, V., M.A. Brow, V.E. Varvel, and J.E. Dahlberg. 1999. Polymorphism identification and quantitative detection of genomic DNA by invasive cleavage of oligonucleotide probes. Nat. Biotechnol. 17:292-296.

64.Mamone, A.J., M. Davis, and D. Sha. 1998. Thermostable DNA polymerase from Thermoanaerobacter thermohydrosulfuricus. US Patent 5744312. Amersham Pharmacia Biotech, assignee.

65.Milla, M.A., P.A. Spears, R.E. Pearson, and G.T. Walker. 1998. Use of the restriction enzyme AvaI and exo- Bst polymerase in strand displacement amplification. BioTechniques 24:392-396.

66.Myers, T.W. and D.H. Gelfand. 1991. Reverse transcription and DNA amplification by a Thermus thermophilus DNA polymerase. Biochemistry 30:7661-7666.

67.Nilsson, M., H. Malmgren, M. Samiotaki, M. Kwiatkowski, B.P. Chowdhary, and U. Landegren. 1996. Padlock probes: circularizing oligonucleotides for localized DNA detection. Science 265:2085-2088.

68.Nilsson, M., K. Krejci, J. Koch, M. Kwiatkowski, P. Gustavsson, and U. Landegren. 1997. Padlock probes reveal single-nucleotide differences, parent of origin, and in situ distribution of centromeric sequences in human chromosomes 13 and 21. Nat. Genet. 16:252-255.

69.Oldenburg, M.C. and M. Siebert. 2000. New cleavase fragment length polymorphism method improves the mutation detection assay. BioTechniques 28:351-357.

70.Ollis, D.L., P. Brick, R. Hamlin, N.G. Xuong, and T.A. Steitz. 1985. Structure of large fragment of Escherichia coli DNA polymerase I complexed with dTMP. Nature (London) 313:762-766.

71.Osheroff, W.P., H.K. Jung, W.A. Beard, S.H. Wilson, and T.A. Kunkel. 1999. The fidelity of DNA polymerase beta during distributive and processive DNA synthesis. J Biol. Chem. 
274:3642-3650.

72.Patel, P.H. and L.A. Loeb. 2000. Multiple amino acid substitutions allow DNA polymerases to synthesize RNA. J. Biol. Chem. 275:40266-40272.

73.Perler, F.B., S. Kumar, and H. Kong. 1996. Thermostable DNA polymerases. Adv. Protein Chem. 48:377-435.

74.Riggs, M.G., S. Tudor, M. Sivaram, and S.H. McDonough. 1996. Construction of single amino acid substitution mutants of cloned Bacillus stearothermophilus DNA polymerase I which lack $5^{\prime}$ to $3^{\prime}$ exonuclease activity. Biochim. Biophys. Acta 1307:178-186.

75.Sanger, F., J.E. Donelson, A.R. Coulson, H. Kossel, and D. Fischer. 1973. Use of DNA polymerase I promed by a synthetic oligonucleotide to determine a nucleotide sequence in phage f1 DNA. Proc. Natl. Acad. Sci. USA 70:1209-1213.

76.Sanger, F., S. Nicklen, and A.R. Coulson. 1977. DNA sequencing with chain-terminating inhibitors. Proc. Natl. Acad. Sci. USA 74:5463-5467.

77.Sayers, J.R. and F. Eckstein. 1990. Properties of overexpressed phage T5 D15 exonuclease. Similarities with Escherichia coli DNA polymerase I $5^{\prime}$ to $3^{\prime}$ exonuclease. J Biol. Chem. 265:18311-18317.

78.Simon, M., L. Giot, and G. Faye. 1991. The $3^{\prime}$ to $5^{\prime}$ exonuclease activity located in the DNA polymerase subunit of Saccharomyces cerevisiae is required for accurate replication. EMBO J. 10:2165-2170.

79.Soengas, M.S., J.A. Esteban, J.M. Lazaro, A. Bernard, M.A. Blasco, M. Salas, and L. Blanco. 1992. Site-directed mutagenesis at the exo III motif of $\Phi 29$ DNA polymerase: overlapping structural domains for the $3^{\prime}$ to $5^{\prime}$ exonuclease and strand-displacement activities. EMBO J. 11:4227-4237.

80.Sousa, R., Y.J. Chung, J.P. Rose, and B.C. Wang. 1993. Crystal structure of bacteriophage T7 RNA polymerase at 3.3A resolution. Nature (London) 364:593-599.

81.Southworth, M.W., H. Kong, R.B. Kucera, J.Ware, H.W. Jannasch, and F.B. Perler. 1996. Cloning of thermostable DNA polymerases from hyperthermophilic marine $\mathrm{Ar}$ chaea with emphasis on Thermococcus sp. 9 degrees N-7 and mutations affecting $3^{\prime}$ to $5^{\prime} \mathrm{ex}-$ onuclease activity. Proc. Natl. Acad. Sci. USA 28;93:5281-5285.

82.Steitz, T.A. 1993. DNA and RNA dependent DNA polymerases. Curr. Opin. Struct. Biol. 3:31-38

83.Steitz, T.A., S. Smerdon, J. Jager, J. Wang, L.A. Kohlstaedt, J.M. Friedman, L.S. Beese, and P.A. Rice. 1993. Two polymerases: HIV reverse transcriptase and the Klenow fragment of E. coli DNA polymerase I. Cold Spring Harbor Symp. Quant. Biol. 58:459-504.

84.Stocki, S.A., R.L. Nonay, and L.J. RehaKrantz. 1995. Dynamics of bacteriophage T4 DNA polymerase function: identification of amino acid residues that affect switching between polymerase and $3^{\prime}$ to $5^{\prime}$ exonuclease activities. 1995. J. Mol. Biol. 254:15-28.

85.Sweasy, J.B. and L.A. Loeb. 1992. Mam malian DNA polymerase beta can substitute for DNA polymerase I during DNA replication in Escherichia coli. J. Mol. Chem. 267:1407-
1410.

86.Sweasy, J.B. and L.A. Loeb. 1993. Detection and characterization of mammalian DNA polymerase beta mutants by functional com plementation in Escherichia coli. Proc. Natl. Acad. Sci. USA 90:4626-4630.

87.Sweasy, J.B., M. Chen, and L.A. Loeb. 1995 DNA polymerase $\beta$ can substitute for DNA polymerase I in the initiation of plasmid DNA replication. J. Bacteriol. 177:2923-2925.

88. Tabor, S. and C. Richardson. 1995. A single residue in DNA polymerases of Escherichia coli DNA polymerase I family is critical for distinguishing between deoxy- and dideoxyribonucleotides. Proc. Natl. Acad. Sci. USA 92:6339-6343.

89.Tabor, S. and C.C. Richardson. 1990. T7 DNA polymerase. US Patent 4946786. Harvard University, assignee.

90.Tabor, S. and C.C. Richardson. 1989A. Selective inactivation of the exonuclease activity of bacteriophage T7 DNA polymerase by in vitro mutagenesis. J. Biol. Chem 254:64476448.

91.Tabor, S. and C.C. Richardson. 1989B. Effect of manganese ions on the incorporation of dideoxynucleotides by bacteriophage DNA polymerase and E. coli DNA polymerase I. Proc. Natl. Acad. Sci. USA86:4076-4080.

92.Tabor, S. and C.C. Richardson. 1987. DNA sequence analysis with a modified T7 DNA polymerase. Proc. Natl. Acad. Sci. USA 84:4767-4771.

93.Takagi, M., M. Nishioka, H. Kakihara, M. Kitabayashi, H. Inoue, B. Kawakami, M. Oka, and T. Imanaka. 1997. Characterization of DNA polymerase from Pyrococcus sp. strain KOD1 and its application to PCR. Appl. Environ. Microbiol. 63:4504-4510.

94.Tang, M., X. Shen, E.G. Frank, M. O'Donnell, R. Woodgate, and M.F. Goodman. 1999. $\operatorname{UmuD}(2) \mathrm{C}$ is an error-prone DNA polymerase, Escherichia coli pol V. Proc. Natl. Acad. Sci. USA 96:8919-8924.

95.Thomas, D.C., G.A. Nardone, and S.K. Randall. 1999. Amplification of padlock probes for DNA diagnostics by cascade rolling circle amplification or the polymerase chain reaction. Arch. Pathol. Lab. Med. 123:11701176.

96. Timsit, Y. 1999. DNA structure and polymerase fidelity. J. Mol. Biol. 293:835-853.

97.Truniger, V., J. Lazaro, M. Salas, and L. Blanco. 1996. A DNA binding motif coordinating synthesis and degradation in proofreading DNA polymerases. EMBO J. 15:34303441.

98.Uemori, T., Y. Ishino, K. Fujita, K. Asada, and I. Kato. 1993. Cloning of the DNA polymerase gene of Bacillus caldotenax and characterization of the gene product. J. Biochem. (Tokyo) 113:401-410.

99.Uemori, T., Y. Sato, I. Kato, H. Doi, and Y. Ishino. 1997. A novel DNA polymerase in the hyperthermophilic archeon, Pyrococcus furiosus; gene cloning, expression and characterization. Genes Cells 2:499-512.

100.Vander Horn, P.B., M.C. Davis, J.J. Cunniff, C. Ruan, B.F. McArdle, S.B. Samols, J. Szasz, G. Hu et al. 1997. Thermo Sequenase $^{\mathrm{TM}}$ DNA polymerase and $T$. acidophilum pyrophosphatase: new thermostable enzymes for DNA sequencing. BioTechniques 22:758765.

101. Wagner, J., P. Gruz, S.R. Kim, M. Yamada, K. Matsui, R.P. Fuchs, and T. Nohmi. 1999. The dinB gene encodes a novel $E$. coli DNA polymerase, DNA pol IV, involved in mutagenesis. Mol. Cell. 4:281-328.

102.Walker, G.T., M.C. Little, J.G. Nadeau, and D.D. Shank. 1992. Isothermal in vitro amplification of DNA by a restriction enzyme/ DNA polymerase system. Proc. Natl. Acad. Sci. USA 89:392-396.

103.Walker, G.T., M.S. Fraiser, J.L. Schram, M.C. Little, J.G. Nadeau, and D.P. Malinowski. 1992. Strand displacement amplification - an isothermal, in vitro DNA amplification technique. Nucleic Acids Res. 20: 1692-1696.

104.Wang, J., A.K. Sattar, C.C. Wang, J.D. Karam, W.H. Konigsberg, and T.A. Steitz. 1997. Crystal structure of a pol alpha family replication DNA polymerase from bacteriophage RB69. Cell 89:1087-1099.

105.Whiting, S.H. and J.J. Champoux. 1998. Properties of strand displacement synthesis by Moloney murine leukemia virus reverse transcriptase: mechanistic implications. J. Mol. Biol. 278:559-577.

106. Wu, H., Z. Hu, and X.-Q. Liu. 1998. Protein trans-splicing by a split intein encoded in a split DnaE gene of Synechocystis sp. PCG 6803. Proc. Natl. Acad. Sci. USA 95:92269231.

Address correspondence to:

Dr. Maria C. Davis

Research and Development

Amersham Pharmacia Biotech

800 Centennial Avenue

Piscataway, NJ 08855-1327

e-mail: maria.davis@am.apbiotech.com

For reprints of this or any other article, contact Reprints@BioTechniques.com 